$\underline{\text { Review Article }}$

\title{
MOLECULAR DOCKING: AN EXPLANATORY APPROACH IN STRUCTURE-BASED DRUG DESIGNING AND DISCOVERY
}

\section{ADITI SHARMA ${ }^{1}$, SALONI KUNWAR ${ }^{1}$, VAISHALI ${ }^{1}$, VAISHALI AGARWAL ${ }^{1}$, CHHAYA SINGH $^{2}$, MANISH DEV SHARMA ${ }^{3}$, NEHA CHAUHAN*}

${ }^{1}$ Department of Biotechnology, Life Sciences Graphic Era (Deemed To Be) University, Dehradun (Uttarakhand), ${ }^{2}$ Govt. College Thallisain, Pauri Garhwal (Uttarakhand), ${ }^{3}$ Department of Biotechnology, School of Basic and Applied Sciences, Shri Guru Ram Rai University, Dehradun (Uttarakhand). *Department of Microbiology, SGRRIMHS College of Paramedical Sciences, Shri Guru Ram Rai University, Dehradun Email: chauhanneha7777@gmail.com

Received: 19 Jan 2021, Revised and Accepted: 20 Apr 2021

\section{ABSTRACT}

Molecular docking is a modeling tool of Bioinformatics which includes two or more molecules which interact to provide a stable product in the form of a complex. Molecular docking is helpful in predicting the 3-d structure of a complex which depends on the binding characteristics of Ligand and target. Also, it is a structure-based virtual screening (SBVS) utilized to keep the 3-d structures of small molecule which are generated by computers into a target structure in various types of conformations, positions and orientations. This molecular docking has come out to be a novel concept with various types of advantages. It behaves as a highly exploring domain due to its significant structure-based drug design (SBDD), Assessment of Biochemical pathways, Lead Optimization and in De Novo drug design. In spite of all potential approaches, there are certain challenges which arescoring function (differentiate the true binding mode), ligand chemistry (tautomerism and ionization) and receptor flexibility (single conformation of rigid receptor). The area of computer-aided drug design and discovery (CADDD) has achieved large favorable outcomes in the past few years. CADD has been adopted by various big pharmaceutical companies for leading discoveries of drugs. Many researchers have worked in order to examine different docking algorithms and to predict molecules' active site. Hence, this Review article depicts the whole sole of Molecular Docking.

Keywords: Molecular Docking, Drug Discovery, Conformations, Ligand, Optimization, Protein Flexibility

(C) 2021 The Authors. Published by Innovare Academic Sciences Pvt Ltd. This is an open access article under the CC BY license (https://creativecommons.org/licenses/by/4.0/)

DOI: https://dx.doi.org/10.22159/ijpps.2021v13i6.40830. Journal homepage: https://innovareacademics.in/journals/index.php/ijpps.

\section{INTRODUCTION}

Molecular Docking involves the anticipation of the recommended conformation of the ligand against receptor (Protein) to achieve a complex which is stable [1]. These recommended orientations are thus used in predicting the affinity of binding amongst the ligand and protein by the help of scoring functions. Thus Docking mainly aims at anticipating the binding orientations of drug candidates in response to a particular target protein to check the activity of the drug molecule in order to achieve a specific drug design and discovering a novel drug (fig 1). But there is a requirement of previous knowledge of the favorable orientation predicting the binding strength of two molecules by the help of a scoring function. Docking also aims at the formation of rational drug designs by attaining a stable ligand-receptor complex with minimum binding free energy [2]. There are various factors that predict the binding free energy ( $\Delta$ Gbind) displayed in the form of different parameters such as-electrostatic $(\Delta \mathrm{Gelec})$, hydrogen bond ( $\Delta$ Ghbond), torsional free energy $(\Delta \mathrm{G}$ tor), desolvation $(\Delta \mathrm{Gdesolv})$, dispersion and repulsion $(\Delta \mathrm{Gvdw})$, total internal energy ( $\Delta \mathrm{Gtotal})$ and unbound energy of system ( $\Delta$ Gunb). Consequently, one needs a profound knowledge about the common ethics governing the prediction of binding free energy ( $\Delta$ Gbind) providing extra indications of interacting molecules which will lead to the stable docking procedures [3]. Also the docking technique aims at computationally simulating the process of identification of molecules and achieving a better conformation so as to minimize the overall free energy of the system. It is very difficult to discover a new drug. In silico-chemico biological approaches are the main bases of modern drug discovery. A lot of popularity, implementation and appreciation had been gained by the use of computer-aided procedures in the discovery of drugs and generation procedures. There are multiple software and tools which can be utilized in Computer-aided Drug Design (CADD) including-Auto-Dock (http://vina.scripps.edu/), DOCK (http://dock.compbio.ucsf.edu/), FlexX (https://dblp.org/pid/64/5059.html), Glide (https://www.schrodinger.com/products/glide), GOLD (https://www.ccdc.cam.ac.uk/support-and-resources/ccdcresources/) and Ligand Fit (https://www.phenix-online.org/).

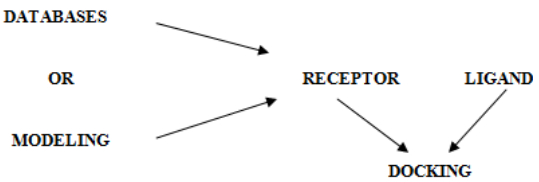

Fig. 1: Basic molecular docking procedure [2]

\section{Computational approaches to drug discovery or CADD}

Computer-aided Drug Design (CADD) is an extensively used term since 1980. It represents the computer-based approaches as a tool and a source for the storing, managing, analyzing and modeling of compounds. Various features of drug discovery can be explored by the CADD approach like the designing of compounds, studying chemical interactions and assessment of potentially leading candidates [4]. CADD can be principally applied to achieve the identification, validation and optimization of the target molecule and even for the preclinical trials [5-8]. The cost for the development of drugs can be decreased up to 50\%by the CADD approach [9]. The virtual screening involves the examination of a large no. of databases of compounds to search for the binding capacity for a target. Out of the huge databases, an appropriate subset of compounds is selected. This technique thus reduces the amount of compounds to be tested by conducting various experiments and enhancing the hit rate of novel drugs [10]

a. The computational approach is beneficial in drug designing and development.

b. Novel Drug discovery and optimization can be achieved by the chemical and biological information gathered about the target and the ligand from the computational databases.

c. Some in silico filters have been designed to remove chemical compounds with unwanted properties and for the selection of the most appropriate candidate. 
d. By the use of computational approaches, it becomes easy to identify the novel drug target. Also the protein data bank proves to be a promising tool for the retrieval of target protein structure (fig. 2).

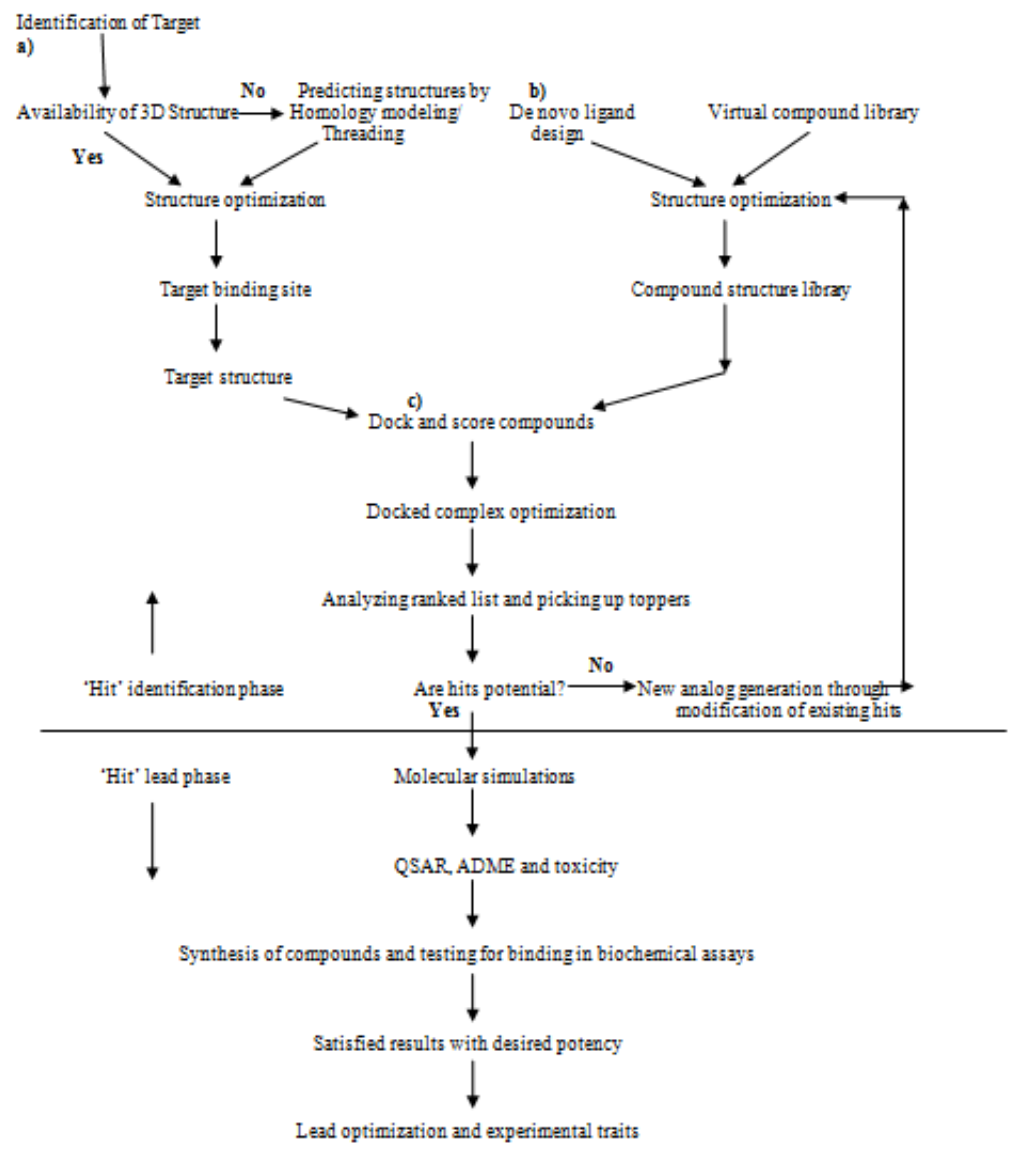

Fig. 2: Computational approaches to drug discovery [3]

e. The application of virtual screening can be seen in finding novel drug candidates from different chemical sets by inquiring about the databases $[11,12]$.

\section{Various interactions involved in the docking procedure}

There can be four different types of Interaction forces:

(1) Electrodynamics forces-Van der Waals interaction.

(2) Electrostatic forces-dipole-dipole, charge-dipole and charge-charge

(3) Solvent-related forces-Hydrogen bond and hydrophobic interactions

(4) Steric forces-Caused by entropy $[13,14]$.

The docking procedure aims at predicting one of the best approaches of binding ligands with its suitable macromolecular partner which is most often a protein. This technique thus generates possible orientations in the form of ligand poses in a huge amount inside the binding site of the protein. Thus, it necessitates the presence of the 3-d structure of the targeted molecule. This structure can be any of the type, either achieved after conducting various experiments like X-ray crystallography/Nuclear Magnetic Resonance or by utilizing various computer-aided techniques like homology modeling [15]. Molecular docking involves two main stages: a search algorithm and a scoring function, which is associated with a score predicting every conformation [16-18].

\section{Search algorithm}

The searched algorithm must be able to generate the most favorable amount of configurations to be admitted by conduction of many experiments to determine modes of binding. There exist many relevant algorithms for analyzing docking procedures like Point complementary, Monte Carlo, Fragment-based, Genetic algorithms, Systematic searches, Distance geometry etc., [19, 20].

\section{Various docking approaches}

\section{Monte carlo approach}

This approach is beneficial in generating an initial orientation of a ligand at the active site which possesses translation, random conformation rotation. The starting orientation can be scored from it and it can also score a new configuration after generating it. A metropolis criterion is useful in the determination of the retaining ability of a new configuration. (Metropolis criterion is based on the immediate acceptance of new solution scores only when it is better than the previous one. In case a configuration is not found to be new, the application of a Boltzmann-based probability function is done, which finally decides if the configuration is accepted or rejected on the basis of the passing of the probability function test.

\section{Fragment-based method}

This method as the name suggests, mainly depends on the division of ligands in the form of fragments or small protons followed by the docking procedure and finally the linking of docked fragments is performed.

\section{Distance geometry}

Information about the structure has been utilized by the Distance Geometry to be conveyed as intra or intermolecular distances. First of all, this geometry assembles the distance and then the consistency of 3-d structures is calculated with these distances. 


\section{Matching approach}

The main basis of this approach is the complementarity between the ligand and the protein. In this approach, the ligand-receptor configuration is generated by placing the ligand atom at the best site of the protein. This configuration, thus formed may need to be optimized further.

\section{Ligand fit approach}

The base of this approach is the shape resemblance between ligand and protein active sites. Hence, it is beneficial in the rapid and accurate methods for docking of smaller molecule ligands into the active sites of protein.

\section{Point complementarity approach}

This approach aims at evaluating the shape and chemical complementarity between the molecules forming specific interactions.

\section{Blind docking}

This docking approach is used in the detection of binding sites which are possible. Also in identifying the fashion of peptide ligand by overall surface scanning of the targeted proteins.

\section{Inverse docking}

This docking procedure utilizes computational methods to detect the toxicity and side effect of small molecular protein targets. The understanding of these proteins facilitates the side effects and toxicities of the drug molecules by the combined effects of proteomics and pharmacokinetic profile [21-23].

\section{Scoring function}

This function is also an important constituent of protein-ligand docking protocols. Mainly, this function is utilized in the estimation and ranking of the conformational binding which are produced with the help of search algorithms. The score thus obtained after the ranking, directly corresponds to the ligands binding affinity so that the ligands with the topmost score become the best binders. Scoring is drawn up of 3 expressions which are significant to docking and drug designing:

a) Ranking of the orientations produced after docking search.

b) Virtual Screening: To rank different ligands against the protein

c) Selectivity and specificity: To rank one or more than one ligands against different proteins on the basis of their binding affinity [24-27]

Also, the scoring functions act like a pose selector, utilized to differentiate correctly assumed binding fashion and binders for nonbinders in the group of poses produced by the sampling engine/search algorithm. The 3 main kinds of scoring functions are:

\section{Force-field based scoring functions}

This function proceeds the potential energy of a system by combined effects of bonded (intramolecular) and non-bonded (intermolecular) constituents. In molecular docking, more preference is given to the non-bonded components, by possibly adding the ligand-bonded terms, especially the torsional components. Intermolecular components mainly include the van der Waals forces, the electrostatic potential and the solvation energy to some extent [28]. Some of the examples of this scoring function includes-Gold Score and Auto Dock. Auto Dock is a multifaceted protein-ligand docking procedure offering various search algorithms like Monte Carlo Simulated Annealing algorithm, Genetic Algorithm (GA), and hybrid local search GA [Lamarckian Genetic Algorithm (LGA)]. The use of auto doc tools can be done with a visual interface called Auto Dock Tools (ADT) ensuring an adequate investigation of the docking results. While GOLD is a considerable protein-ligand docking program, allowing full ligand flexibility. It also ensures partial flexibility of proteins as its side-chain and backbone flexibility, which can be utilized by almost ten user-defined residues [29-31].

\section{Empirical scoring functions}

It is the combining effect of many empirical energy terms like electrostatic, van der Waals, hydrogen bond, entropy, desolvation and hydrophobicity [32]. Glide score, FlexX [33], and LUDI [34, 35] are examples of this scoring function. Glide score has proved to be an integrated explication for protein-ligand docking, which is accessible as a module in the Schrodinger software suite, managed by the Schrodinger LLC [36, 37]. Glide has been capable of gaining a considerable amount of users in a very short span of time for about a few years and is becoming prominent as an animating option for protein-ligand docking. Glide is capable of generating set of grids with various kinds of fields depicting geometries and characteristics of the bonding site region of the receptor [38, 39].

\section{Knowledge-based scoring functions}

These functions are called by another name which is the statistical potential-based scoring functions. Their development has been done by the statistical examination of the atom pairs that are visible in a training data set. The Inverse-Boltzmann equation defines the relationship of structural features frequency and the interaction energies allotted to those features [40]. This scoring function is able to maintain more balance between accuracy and speed as compared with the other scoring functions. But it lacks behind from the others by being trained set-dependent. Some examples of this function include the potential of mean force (PMF) $[41,42]$ and IT Score [4348]

\section{Various types of docking}

During the 1980s, the very first algorithm for docking procedures was developed [49]. The receptor was optimized by a number of spheres which filled the cleft of its surface while the ligand was filled with one more set of spheres depicting its volume. In order to find out the most favorable steric overlap between receptor spheres and the site of binding a study was conducted by neglecting any type of conformational movement. The docking procedures can thus be differentiated on the basis of degrees of flexibility of the molecules concerned with the calculation [50] (fig. 3):

\section{Rigid docking/lock and key phenomena}

The ligand along with its associated protein are contemplated rigid entities and during the sampling procedure, only three-three each of the translational and rotational degrees of freedom are studied. This estimation is similar to the "lock and key" model for binding and is basically utilized for protein-protein docking where it becomes difficult to sample the amount of conformational degrees of freedom as it is much higher. These methods mainly involve optimization of the binding site and the ligand with hot points and the evaluation of superposition of matching points [51]

\section{Semi-flexible docking}

Out of the ligand and protein, the former is flexible and the latter is rigid. Hence, the sampling of the conformational degrees of freedom of the ligand is done along with the 6 translational and rotational ones. These procedures presume that a ligand which is to be docked can be recognized by the fixed orientation of a protein.

\section{Flexible docking/Induced fit model}

This method focuses on the concept of both protein and ligand to be flexible equivalents of each other at the time of binding. It involves either the utilization of an induced fit model or the conformational selection.

\section{Molecular docking technique: steps involved}

The technique involves the In silico study of intermolecular interaction between two molecules i.e. a ligand and receptor, where the protein receptor is a macromolecule and the ligand is a macromolecule that acts as an inhibitor. The technique constitutes:

\section{Preparation of protein}

The first step involves the retrieval of the 3-d structure of the protein from the Protein data bank (PDB); and the structure thus obtained is allowed for pre-processing. This step also capacitates to remove water molecules from the cavity, for the stabilization of charges, filling the missing residues and formation of side chains on the basis of present parameters. 


\section{Prediction of active site}

The preparation of protein is followed by the prediction of its active site. A lot of active sites may be possessed by the receptor, but the one which is accurately concerned with the ligand is selected. But the water molecules and hetero atoms if present, are then withdrawn $[52,53]$.

\section{Preparation of ligand}

Ligands can be retrieved from several databases such as ZINC, Pub Chem or can be sketched applying Chem sketch tool. While picking out the ligand, the LIPINSKY'S RULE OF 5 should be utilized. Lipinski rule of 5 assists in discerning amongst non-drug like and drug like candidates. It promises high chance of success or failure due to druglikeness for molecules abiding two or more than two rules. For choice of a ligand allowing to the LIPINSKY'S RULE:
a) Less than five hydrogen bond donors
b) Less than ten hydrogen bond acceptors
c) Molecular mass less than $500 \mathrm{Da}$
d) High lipophilicity (expressed as LogP not over 5)
e) Molar refractivity should be between 40-130

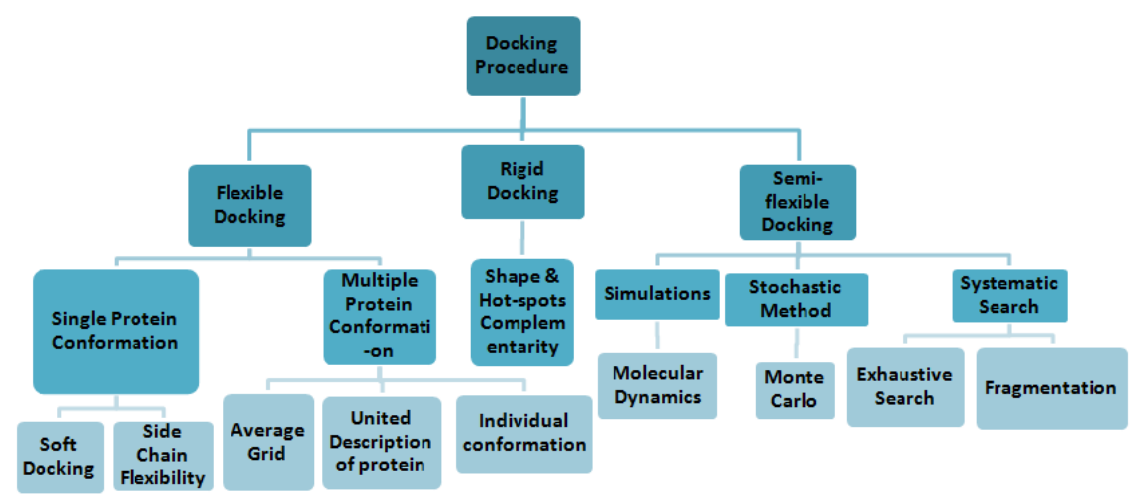

Fig. 3: Various docking procedures [50]

\section{Energy minimization}

The ligand is the main candidate for this procedure as it can attain various orientations. The one with minimum energy will be considered the best and most stable ligand conformation. The two different types of energies are:

a) Electrostatic potential energy: It is a pairwise summation of coulombic interactions as described in equilibrium.

$$
E(r)=\sum_{i=1}^{N_{A}} \sum_{j=1}^{N_{B}} \frac{q_{i} q_{j}}{4 \pi \varepsilon_{0} r_{q}}
$$

In Equation $\mathrm{N}=$ the number of atoms in molecules $\mathrm{A}$ and $\mathrm{B}$ respectively $\mathrm{q}=$ charge on each atom.

b) Van Der Waals Potential Energy: The general treatment of nonbonded interactions is often modeled by a Lennard-Jones 12-6 function as in equilibrium mentioned in the equation:

$$
E(r)=\sum_{j=1}^{N} \sum_{i=1}^{N} 4 \varepsilon\left[\left(\frac{\sigma_{n}}{r_{q}}\right)^{12}-\left(\frac{\sigma_{n}}{r_{q}}\right)^{6}\right]
$$

$\mathrm{S}=$ is the well depth of the potential

$s=$ is the collision diameter of respective atoms $i$ and $j$

\section{Verification of docking software packages}

There is a huge availability of various software packages in the market for molecular docking. The relative assessment is performed for the identification of the most promising software package which can predict the nearest match to the crystallographic data on the protein-ligand complex-

a) A familiar standard ligand is selected, e. g. Nevirapine

b) X-ray crystallography is used to predict the coordinates of the binding position of Nevirapine and coordinates of active site amino acids experimentally.

c) A ligand is taken and is docked into the active site of various enzyme software packages, now, translation and rotation of ligand are done totally. Then the final binding energy is determined followed by its grading.

d) The comparison of the most stable ligand fit is performed by Xray crystallographic binding coordinates. This can lead to the selection of the most favorable software package for the study of docking procedures.

\section{Docking}

The last step involves the docking of the ligand against its corresponding protein and the interaction between the two is examined. The scoring function thus provides the score on behalf of the most effectively docked ligand-protein complex and then this complex is apparently selected.

\section{Docking software}

Throughout the last twenty years, many docking procedures have been drawn up table (1) [54-56].

\section{Applications}

The activation or inhibition of the protein is achieved by molecular docking while the ligand binding leads to agonism or antagonism. Some of the applications include:

1. For evaluating various databases to discover the most powerful drug candidate [61].

2. Prediction of optimized conformation of ligand on its target [62, 63].

3. Bioremediation

4. Checking Biological activities by predicting Ka values

5. Prediction of binding sites

6. Adoption of orphan receptor protein

7. To study interactions between proteins

8. To seek leading structures for protein targets

10. To study enzymatic reaction procedures

11. Protein engineering 
Table 1: Properties of currently available molecular docking tools [55]

\begin{tabular}{|c|c|c|c|c|c|c|c|}
\hline S. No. & $\begin{array}{l}\text { Different } \\
\text { tools }\end{array}$ & $\begin{array}{l}\text { Name of designer/ } \\
\text { Company }\end{array}$ & $\begin{array}{l}\text { Licensing } \\
\text { terms }\end{array}$ & $\begin{array}{l}\text { Assisted } \\
\text { platforms }\end{array}$ & $\begin{array}{l}\text { Approach for } \\
\text { docking }\end{array}$ & $\begin{array}{l}\text { Scoring } \\
\text { function }\end{array}$ & References \\
\hline I & Auto Dock & $\begin{array}{l}\text { D. S. Good sell } \\
\text { and A. J. Olson } \\
\text { The Scripps } \\
\text { Research Institute }\end{array}$ & $\begin{array}{l}\text { Free for } \\
\text { Academic } \\
\text { Use }\end{array}$ & $\begin{array}{l}\text { Unix, Mac } \\
\text { OSX, } \\
\text { Linux, SGI }\end{array}$ & $\begin{array}{l}\text { Genetic } \\
\text { Algorithm } \\
\text { Lamarckian } \\
\text { Genetic } \\
\text { Algorithm } \\
\text { Simulated } \\
\text { Annealing }\end{array}$ & $\begin{array}{l}\text { Auto Dock } \\
\text { (force-field } \\
\text { methods) }\end{array}$ & 13 \\
\hline II & DOCK & $\begin{array}{l}\text { I. Kuntz } \\
\text { University of } \\
\text { California, } \\
\text { San Francisco }\end{array}$ & $\begin{array}{l}\text { Free for } \\
\text { Academic use }\end{array}$ & $\begin{array}{l}\text { Unix, Linux, } \\
\text { Sun, IBM } \\
\text { AIX, Mac } \\
\text { OSX, Windows }\end{array}$ & $\begin{array}{l}\text { Shape fitting } \\
\text { (sphere sets) }\end{array}$ & $\begin{array}{l}\text { Chem Score, } \\
\text { GB/SA } \\
\text { solvation } \\
\text { scoring, other }\end{array}$ & 57 \\
\hline III & Flex X & $\begin{array}{l}\text { T. Lengauer and } \\
\text { M. Rarey } \\
\text { BioSolvelT }\end{array}$ & $\begin{array}{l}\text { Commercial } \\
\text { Free evaluation } \\
(6 \mathrm{w})\end{array}$ & $\begin{array}{l}\text { Unix, Linux, } \\
\text { SGI, Sun } \\
\text { Windows }\end{array}$ & $\begin{array}{l}\text { Incremental } \\
\text { Construction }\end{array}$ & $\begin{array}{l}\text { FlexXScore, } \\
\text { PLP, Screen } \\
\text { Score, Drug } \\
\text { Score }\end{array}$ & 58 \\
\hline IV & Glide & Schrödinger Inc. & Commercial & $\begin{array}{l}\text { Unix, Linux, } \\
\text { SGI, IBM } \\
\text { AIX }\end{array}$ & $\begin{array}{l}\text { Monte Carlo } \\
\text { Sampling }\end{array}$ & $\begin{array}{l}\text { Glide Score, } \\
\text { Glide Comp }\end{array}$ & 59 \\
\hline V & GOLD & $\begin{array}{l}\text { Cambridge } \\
\text { Crystallographic } \\
\text { Data Centre }\end{array}$ & $\begin{array}{l}\text { Commercial } \\
\text { Free evaluation } \\
(2 \mathrm{mo})\end{array}$ & $\begin{array}{l}\text { Linux, SGI, } \\
\text { Sun, IBM, } \\
\text { Windows }\end{array}$ & $\begin{array}{l}\text { Genetic } \\
\text { Algorithm }\end{array}$ & $\begin{array}{l}\text { Gold Score, } \\
\text { Chem Score } \\
\text { user defined }\end{array}$ & 60 \\
\hline VI & Ligand Fit & Accelrys Inc. & Commercial & $\begin{array}{l}\text { Linux, SGI, } \\
\text { IBM AIX }\end{array}$ & $\begin{array}{l}\text { Monte Carlo } \\
\text { Sampling }\end{array}$ & $\begin{array}{l}\text { Lig Score, } \\
\text { PLP, PMF }\end{array}$ & 26 \\
\hline
\end{tabular}

\section{Basic challenges}

\section{Ligand chemistry}

The docking results are prominently affected by the ligand preparation because the recognition of ligand by any biomolecule is dependent on 3-d confirmation and electrostatic interaction. This proves the importance of orientation and preparation of ligands. By removing or adding hydrogens the structure to be docked can be optimized, but the tautomeric and protomeric molecular states still become the major inconsistency. The molecules remain in their neutral forms by all databases but under certain physiological conditions, they are actually ionized. Since molecules are kept in their neutral form of almost all the databases, but they are actually ionized under physiological conditions. Thus, their ionization is required to be done before docking. But this standard ionization can be achieved easily through different programs. Concerning the matter of tautomers, there still remains a problem of selecting one tautomer out of the all others [64].

\section{Receptor flexibility}

The receptor flexibility, i.e. the handling of flexible protein is a major issue of molecular docking. Different conformations are adopted by a protein which depends on the binding ligand. This ensures the occurrence of a single receptor orientation when the docking is performed using a rigid receptor. Although, the ligands may need various receptor orientations to bind, when the docking is performed with a flexible receptor. In understanding the concept of molecular docking, the most varied orientation states of proteins are the most neglected features. Since the protein flexibility depicts the achievement of better affinity between a present drug and target, hence is important. Active site water molecules are one more feature of target flexibility. To avoid the use of artifact waters in the docking procedure, the water should be rectified [65].

\section{FUNCTION}

The defect in the scoring function is also a major challenge of docking. The scoring function aims at discriminating between the correct binding modes and all other aligned modes. The scoring functions create various proposals for evaluating the affinity of ligands when there is accuracy. Entropy and electrostatic interactions, which are physical phenomena, are disregarded in scoring schemes. With reference to accuracy and speed, the absence of applicable scoring function is the major obstruction in the molecular docking procedures [66].

\section{CONCLUSION}

The docking procedures have come out to be one of the most favorable techniques in the field of drug designing, especially in the past few years. This could be possible by the increased availability of various software used in docking, its advanced approaches and the rapidly growing users. Along with all the enhancing benefits, some problems are also to be faced while performing molecular docking. This mainly involves the achievement of efficient protein flexibility during searching algorithms and the presence of water molecules along with entropy treatments during scoring function. But there are a varied number of software available to overcome these problems and new alternatives are also continuously appearing in each upcoming year. Though in this rapidly growing field all the alternatives will become outdated sooner or later especially if not updated timely. So, the early adopters own a special benefit here as it is difficult to master a newly formed software.

\section{ACKNOWLEDGMENT}

All authors have equally contributed to the article.

\section{AUTHORS CONTRIBUTIONS}

All the authors are equally contributed

\section{CONFLICT OF INTERESTS}

Authors have declared no conflicts of interest.

\section{REFERENCES}

1. Lengauer T, Rarey M. Computational methods for biomolecular docking. Curr Opin Struct Biol 1996;6:402-6.

2. Kitchen DB, Decornez H, Furr JR, Bajorath J. Docking and scoring in virtual screening for drug discovery: methods and applications. Nat Rev Drug Discovery 2004;3:935-49.

3. Agarwal S, Chadha D, Mehrotra R. Molecular modeling and spectroscopic studies of semustine binding with DNA and its comparison with lomustine-DNA adduct formation. J Biomol Struct Dyn 2015;33:1653-68.

4. Song CM, Lim SJ, Tong JC. Recent advances in computer-aided drug design. Brief Bioinform 2009;10:579-91.

5. Shekhar C. In silico pharmacology: computer-aided methods could transform drug development. Chem Biol 2008;15:413-4.

6. Jorgensen WL. The many roles of computation in drug discovery. Sci 2004;303:1813-8.

7. Xiang M, Cao Y, Fan W, Chen L, Mo Y. Computer-aided drug design: lead discovery and optimization. Comb Chem High Throughput Screen 2012;15:328-37. 
8. Zhang S. Computer-aided drug discovery and development. Methods Mol Biol 2011;716:23-38.

9. Tan JJ, Cong XJ, Hu LM, Wang CX, Jia L, Liang XJ. Therapeutic strategies underpinning the development of novel techniques for the treatment of HIV infection. Drug Discovery 2010;15:186-97.

10. Salmaso V. Exploring protein flexibility during docking to investigate ligand-target recognition. Ph. D. thesis, University of Padova, Padova; 2018.

11. Pozzan A. Molecular descriptors and methods for ligand-based virtual high throughput screening in drug discovery. Curr Pharm Des 2006;12:2099-110.

12. Green DV. Virtual screening of virtual libraries. Progr Med Chem 2003;41:61-97.

13. Goodsell DS, Olson AJ. Automated docking of substrates to proteins by Simulated Annealing. Proteins 1990;8:195-202.

14. Kuntz ID, Blaney JM, Oatley SJ, Langridge R, Ferrin TE. A geometric approach to macromolecule-ligand interactions. J Mol Biol 1982;161:269-88.

15. Salmaso V, Sturlese M, Cuzzolin A, Moro S. Combining self and cross-docking as benchmark tools: the performance of dock bench in the D3R grand challenge 2. J Comput Aided Mol Des 2018;32:251-64.

16. Abagyan R, Totrov M. High-throughput docking for lead generation. Curr Opin Chem Biol 2001;5:375-82.

17. Kitchen DB, Decornez H, Furr JR, Bajorath J. Docking and scoring in virtual screening for drug discovery: methods and applications. Nat Rev Drug Discovery 2004;3:935-49.

18. Huang SY, Zou X. Advances and challenges in protein-ligand docking. Int J Mol Sci 2010;11:3016-34.

19. Rarey M, Kramer B, Lengauer T. Multiple automatic base selection: protein-ligand docking based on incremental construction without manual intervention. J Comput Aided Mol Des 1997;11:369-84.

20. Schulz Gasch T, Stahl M. Binding site characteristics in structure-based virtual screening: evaluation of current docking tools. J Mol Model 2003;9:47-57.

21. Goldman BB, Wipke WT. QSD quadratic shape descriptors. 2. Molecular docking using quadratic shape descriptors (QSDock). Proteins 2000;38:79-94.

22. Meng EC, Shoichet BK, Kuntz ID. Automated docking with gridbased energy evaluation. J Comput Chem 2004;13:505-24.

23. Morris GM, Goodsell DS, Halliday RS, Huey R, Hart WE, Belew RK, Olson AJ. Automated docking using a lamarckian genetic algorithm and an empirical binding free energy function. J Comput Chem 1998;19:1639-62.

24. Friesner RA, Banks JL, Murphy RB, Halgren TA, Klicic JJ, Mainz DT, et al. Glide: A new approach for rapid, accurate docking and scoring. 1. Method and assessment of docking accuracy. J Med Chem 2004;47:1739-49.

25. Jones G, Wilett P, Glein RC, Leach AR, Taylor R. Development and validation of genetic algorithm and an empirical binding free energy function. J Mol Biol 1997;267:727-48.

26. Venkatachalam CM, Jiang X, Oldfield T, Waldman M. Ligand fit: a novel method for the shape-directed rapid docking of ligands to protein active sites. J Mol Graph Model 2003;27:289-307.

27. Abagyan RA, Totrov MM, Kuznetsov DA. ICM: a new method for protein modeling and design: applications to docking and structure prediction from the distorted native conformation. ] Comput Chem 1994;15:488-506.

28. Brooijmans N, Kuntz ID. Molecular recognition and docking algorithms. Annu Rev Biophys Biomol Struct 2003;32:335-73.

29. Morris GM, Goodsell DS, Halliday RS, Huey R, Hart WE, Belew RK, et al. Automated docking using a Lamarckian genetic algorithm and an empirical binding free energy function. J Comput Chem 1998;19:1639-62.

30. Goodsell DS, Olson AJ. Automated docking of substrates to proteins by simulated annealing. Proteins 1990;8:195-202.

31. Morris GM, Goodsell DS, Huey R, Olson AJ. Distributed automated docking of flexible ligands to proteins: parallel applications of AutoDock 2.4. J Comput Aided Mol Des 1996;10:293-304

32. Huang SY, Zou X. Advances and challenges in protein-ligand docking. Int J Mol Sci 2010;11:3016-34.

33. Rarey M, Kramer B, Lengauer T, Klebe G. A fast flexible docking method using an incremental construction algorithm. J Mol Biol 1996;261:470-89.
34. Bohm HJ. The development of a simple empirical scoring function to estimate the binding constant for a protein-ligand complex of known three-dimensional structure. J Comput Aided Mol Des 1994;8:243-56.

35. Bohm HJ. Prediction of binding constants of protein ligands: a fast method for the prioritization of hits obtained from de novo design or 3D database search programs. J Compt Aided Mol Des 1998:12:309-23.

36. Friesner RA, Banks JL, Murphy RB, Halgren TA, Klicic JJ, Mainz DT, et al. Glide: a new approach for rapid, accurate docking and scoring. 1. Method and assessment of docking accuracy. J Med Chem 2004;47:1739-49.

37. Halgren TA, Murphy RB, Friesner RA, Beard HS, Frye LL, Pollard WT, et al. Glide: a new approach for rapid, accurate docking and scoring. 2. Enrichment factors in database screening. J Med Chem 2004;47:1750-9.

38. Jorgensen WL, Tirado Rives J. The OPLS [optimized potentials for liquid simulations] potential functions for proteins, energy minimizations for crystals of cyclic peptides and crambin. J Am Chem Soc 1988;110:1657-66.

39. Jorgensen WL, Maxwell DS, Tirado Rives J. Development and testing of the OPLS all-atom force field on conformational energetics and properties of organic liquids. J Am Chem Soc 1996;118:11225-36.

40. Thomas PD, Dill KA. An iterative method for extracting energy-like quantities from protein structures. PNAS USA 1996;93:11628-33.

41. Muegge I, Martin YC. A general and fast scoring function for protein-ligand interactions: a simplified potential approach. J Med Chem 1999;42:791-804.

42. Muegge I. PMF scoring revisited. J Med Chem 2006;49:5895-902.

43. Huang SY, Zou X. An iterative knowledge-based scoring function to predict protein-ligand interactions: I. Derivation of interaction potentials. J Comput Chem 2006a;27:1866-75.

44. Huang SY, Zou X. An iterative knowledge-based scoring function to predict protein-ligand interactions: II. Validation of the scoring function. J Comput Chem 2006b;27:1876-82.

45. Grinter SZ, Yan C, Huang SY, Jiang L, Zou X. Automated large-scale file preparation, docking, and scoring: evaluation of its core and STScore using the 2012 community structure-activity resource benchmark. I Chem Inform Model 2013;53:1905-14.

46. Grinter SZ, Zou X. A bayesian statistical approach of improving knowledge-based scoring functions for protein-ligand interactions. J Comput Chem 2014a;35:932-43.

47. Grinter SZ, Zou X. Challenges, applications, and recent advances of protein-ligand docking in structure-based drug design. Molecules 2014b;19:10150-76.

48. Yan C, Grinter SZ, Merideth BR, Ma Z, Zou X. Iterative knowledge-based scoring functions derived from rigid and flexible decoy structures: evaluation with the 2013 and 2014 CSAR benchmarks. J Chem Inform Model 2016;56:1013-21.

49. Kuntz ID, Blaney JM, Oatley SJ, Langridge R, Ferrin TE. A geometric approach to macromolecule-ligand interactions. J Molecul Biol 1982;161:269-88.

50. Halperin I, Ma B, Wolfson H, Nussinov R. Principles of docking: an overview of search algorithms and a guide to scoring functions. Proteins 2002;47:409-43.

51. Taylor RD, Jewsbury PJ, Essex JW. A review of protein small molecule docking methods. J Comput Aided Mol Des 2002;16:151-66.

52. Mc Martin C, Bohacek RS. QXP: Powerful, rapid computer algorithms for structure-based drug design. J Comput Aided Mol Des 1997;11:333-44.

53. Schnecke V, Kuhn LA. Virtual screening with solvation and ligand-induced complementarity, perspect. Drug Discovery 2000;20:171-90.

54. Jain AN. Surflex: fully automatic flexible molecular docking using a molecular similarity-based search engine. J Med Chem 2003;46:499-511.

55. Wandzik I. Current molecular docking tools and comparisons thereof. Comm Math Comput Chem 2006;55:271-8.

56. Kellenberger E, Rodrigo J, Muller P, Rognan D. Comparative evaluation of eight docking tools for docking and virtual screening accuracy. Proteins 2004;57:225-42.

57. Jha N, Kumar P. Molecular docking studies for the comparative analysis of different biomolecules to target hypoxia inducible factor-1 $\alpha$. Int J Appl Pharm 2017;9:83-9. 
58. Choudhury MD. In silico study for identification of drug like inhibitor from natural compounds against INHA reductase of Mycobacterium tuberculosis. Int J Pharm Pharm 2015;7:232-7.

59. Brindha DP, Kanakam CC, Nithya G. Docking studies for various antibacterial benzilate derivatives. Asian J Pharm Clin Res 2017;10:268-71.

60. Hamsa NS, Nair VP, Chandramohan V, Patel SJ. Pharmacophore elucidation and docking studies on anti-inflammatory compounds of medicinal plants for ulcerative coloitis. Asian J Pharm Clin Res 2013;6:56-61.

61. Ferreira LG, dos Santos RN, Oliva G, Andricopulo AD. Molecular docking and structure-based drug design strategies. Molecules 2015;20:13384-421.
62. Shoichet BK, McGovern SL, Wei B, Irwin JJ. Lead discovery using molecular docking. Curr Opin Chem Biol 2002;6:439-46.

63. Gschwend DA, Good AC, Kuntz ID. Molecular docking towards drug discovery. J Mol Recognit 1996;9:175-86.

64. Elokely KM, Doerksen RJ. Docking challenge: protein sampling and molecular docking performance. J Chem Inform Mode 2013;53:1934-45.

65. Totrov M, Abagyan R. Flexible ligand docking to multiple receptor conformations: a practical alternative. Curr Opin Struct Biol 2008;18:178-84.

66. Cho AE, Rinaldo D. Extension of QM/MM docking and its applications to metalloproteins. J Comput Chem 2009; 30:2609-16. 